\title{
Evaluation of the cardio-ankle vascular index in COVID-19 patients
}

\author{
Ercan Aydın ${ }^{1 *} \oplus$, Aydın Kant $^{2} \odot$, Gürdal Yilmaz ${ }^{3} \odot$
}

\section{SUMMARY}

OBJECTIVE: This study aimed to investigate the relationship and prognostic significance of cardio-ankle vascular index, which is a measure of arterial stiffness that can lead to endothelial dysfunction and poor cardiovascular issues in COVID-19 patients, with COVID-19.

METHODS: The study included 115 patients, of which 65 patients in the case group with Real time reversetranscription-polymerasechainreaction test positive and diagnosed for COVID-19 and 50 volunteers in the control group. Patients with COVID-19 were classified as moderate/severe or mild COVID-19 in the subgroup analysis based on the severity of the disease. We investigated the relationship between cardio-ankle vascular index and COVID-19 by using the VaSera VS-1000 device to automatically measure each patient's cardio-ankle vascular index and ankle-brachial pressure index. RESULTS: The mean age of participants included in the study was $65.7 \pm 10.7$ years. Patients and volunteers were statistically similar in terms of age, gender, comorbidities, Charlson comorbidity index scores, and body mass index values ( $p>0.05)$. The right-cardio-ankle vascular index value was $9.6 \pm 2.4$ in the case group and $8.5 \pm 1.1$ in the control group ( $p=0.004)$. The left-cardio-ankle vascular index value was $9.4 \pm 2.7$ in the case group and $8.5 \pm 1.2$ in the control group ( $p=0.01$ ). The right-cardio-ankle vascular index value was $10.8 \pm 3.4$ in the moderate/severe disease group and $8.8 \pm 0.9$ in the mild disease group ( $p=0.008$ ). The left-cardio-ankle vascular index value was $10.7 \pm 3.6$ in the moderate/severe disease group and $8.5 \pm 1.5$ in the mild disease group $(p<0.001)$. The right-cardio-ankle vascular index and left-cardio-ankle vascular index values were found to be significantly higher in COVID-19 patients in our study. When receiver operating characteristic analysis was performed to distinguish moderate/severe COVID-19 patients from mild patients, right-cardio-ankle vascular index was area under the curve 0.757 (0.630-0.884), and left-cardio-ankle vascular index was area under the curve 0.782 (0.661-0.902).

CONCLUSION: The right-cardio-ankle vascular index and left-cardio-ankle vascular index values increased in COVID-19 patients in our study, and this was thought to be prognostically significant.

KEYWORDS: COVID-19. Arterial stiffness. Cardio ankle vascular index. Endothelium.

\section{INTRODUCTION}

Severe acute respiratory syndrome coronavirus 2 (SARS-CoV-2) causes a disease with a high mortality rate and a proclivity for multiple organ failure by wreaking havoc on various organ systems, particularly the lungs, heart, brain, kidney, and vascular system $^{1}$. Endothelial dysfunction is critical in the pathogenesis of the disease. The endothelium, which is located at the key interface between blood and tissues, acts as a portal that operates white blood cells to enter tissues to fight invaders, microbes, or viruses, and to help repair injury and heal wounds ${ }^{2}$. Normal endothelium has a pattern of anticoagulant, antithrombotic, and profibrinolytic properties and has a basis dynamically regulated to maintain a balance between properties supporting and inhibiting thrombus deposition. Furthermore, the endothelial cell has a variety of defense mechanisms reducing local oxidative stress. This balance is disrupted when stimulated by proinflammatory cytokines, bacterial endotoxins, neutrophil extracellular traps (NETs), and similar molecules. NADPH oxidases producing superoxide anions that contribute to oxidative stress are activated ${ }^{3}$. As a result of all of these circumstances, inappropriate or excessive production of cytokines, such as IL-1 $\alpha$ and IL- $1 \beta$, IL- 6 , and TNF- $\alpha$, results in a situation named "a cytokine storm." Endothelial damage and associated complications occur as a result. Coronavirus disease 2019 (COVID-19) is a disease with irregular endothelial function, and the severity of the disease is closely related to this endothelial dysfunction ${ }^{2}$. Although COVID-19 is initiated by the impact of pneumocytes and alveolar macrophages, impaired endothelial function contributes to the ongoing destruction of SARS-CoV-2 in the lung. Impaired endothelial barrier function results in protein and fluid accumulation in the alveolar space and impaired blood oxygenation. The resulting cytokine storm causes capillary leakage and exacerbation of the adult respiratory syndrome (ARDS) originated from COVID-19 $9^{4,5}$. The most serious problems with this

\footnotetext{
${ }^{1}$ Trabzon Kanuni Education and Research Hospital, Department of Cardiology - Trabzon, Turkey.

${ }^{2}$ Vakfıkebir State Hospital, Department of Chest Diseases - Trabzon, Turkey.

${ }^{3}$ Karadeniz Technical University, Faculty of Medicine, Department of Infectious Diseases and Clinical Microbiology - Trabzon, Turkey.

${ }^{*}$ Corresponding author: ercanaydin112@yahoo.com

Conflicts of interest: the authors declare there is no conflicts of interest. Funding: none.

Received on August 21, 2021. Accepted on September 17, 2021.
} 
disease are lung and cardiovascular anomalies ${ }^{6,7}$. Increased arterial stiffness, which is a vascular functional abnormality, has been shown to be an independent risk factor for cardiovascular disease $^{8}$. Both structural and functional abnormalities can cause arterial stiffness 9 . Viral infections can cause functional vascular damage, such as increased arterial stiffness, which is reversible at the beginning of its course ${ }^{10}$. Thrombotic microangiopathy and endothelial dysfunction generalized with pulmonary embolism and venous thromboembolism in patients infected with COVID-19 have been especially demonstrated in autopsy studies ${ }^{11}$. Endothelial dysfunction and associated arterial stiffness may cause adverse cardiovascular issues in COVID-19 patients. This study aimed to measure the functional change in arterial stiffness that may cause endothelial dysfunction and adverse cardiovascular issues in COVID-19 patients and to determine the prognostic significance of this situation.

\section{METHODS}

The study was a prospective case-control study conducted at Trabzon Vakfikebir State Hospital from October 2020 to April 2021. The study included a total of 115 participants whose COVID-19 status was known. While the case group included 65 people who tested positive for COVID-19 rtRT-PCR, the control group included 50 people who tested negative for COVID-19 rtRT-PCR and had similar demographic features. COVID-19 patients were divided into two groups based on the severity of the disease. Patients with fever, shortness of breath, or a severe cough were classified as having moderate/severe COVID-19, while those who did not have these symptoms were classified as having mild COVID-19. People with known peripheral artery disease, glomerular filtration rate (eGFR) less than $30 \mathrm{ml} / \mathrm{min}$, or malignancy were not included in the study. Baseline characteristics and clinical histories, values of systolic and diastolic blood pressure, urea, creatinine, eGFR at admission, serum lipid profile, body mass index (BMI), cardio-ankle vascular index (CAVI), and ankle-brachial pressure index (ABPI) examinations of all participants were performed. CAVI and ABPI were measured using the VaSera VS-1000 (Fukuda-Denshi Company Ltd., Tokyo, Japan), which is a portable machine.

The study protocol was designed in accordance with the principles of the Declaration of Helsinki, and the approval (no: 23618724/2021/22) of the ethics committee was obtained.

\section{Statistical analysis}

All variables in the study were subjected to descriptive statistical analysis. The Kolmogorov-Smirnov test was used to determine the conformity of data obtained by measures to the normal distribution. Student's t-test was used for data that conform to the normal distribution, and the Mann-Whitney $\mathrm{U}$ test was used for data that did not conform to the normal distribution. In the analysis of categorical variables, the chi-square test was used. The data obtained by measurements were expressed as mean \pm standard deviation. The data obtained by scoring were expressed by numbers (\%). The sensitivity and specificity of the statistically significant variables were calculated using the receiver operating characteristic (ROC) curve analysis. $\mathrm{p}<0.05$ was accepted as statistically significant.

\section{RESULTS}

The study included 65 COVID-19 patients in the case group and 50 volunteers in the control group. Volunteers are people who have tested negative for the COVID-19 rtRT-PCR test and have no other disease symptoms. Patients with COVID-19 were aged $67 \pm 12.3$ years, and the volunteers were aged $64.5 \pm 9.2$ years $(p=0.213)$. Patients and volunteers were statistically similar in terms of age, gender, comorbidities, Charlson comorbidity index (CMI) scores, and BMI values ( $\mathrm{p}>0.05)$. Systolic blood pressure, one of the hemodynamic parameters, was $127.5 \pm 19.8$ in the case group and $140.8 \pm 24.7$ in the control group $(\mathrm{p}=0.002)$. Both groups had similar diastolic blood pressure $(\mathrm{p}=0.174)$. The R-CAVI value was 9.62.4 in the case group and 8.51.1 in the control group $(\mathrm{p}=0.004)$. The L-CAVI value was $9.4 \pm 2.7$ in the case group and 8.5 \pm 1.2 in the control group $(\mathrm{p}=0.01)$. The R-ABI and L-ABI values in both groups were similar ( $p>0.05)$. Demographic characteristics, laboratory findings, hemodynamic parameters, and arterial stiffness measurements of patients and volunteers are presented in Table 1.

In our internal evaluation of COVID-19 patients, 25 patients were classified as having moderate/severe disease and were hospitalized, while 40 patients were classified as having mild disease and were treated as outpatients. In the analysis between both groups, gender and age were statistically similar. Hypertension was more common among patients in the moderate/severe disease group ( $\mathrm{p}=0.004)$. The $\mathrm{R}-\mathrm{CAVI}$ value was $10.8 \pm 3.4$ in the moderate/severe disease group and $8.8 \pm 0.9$ in the mild disease group ( $\mathrm{p}=0.008)$. The $\mathrm{L}-\mathrm{CAVI}$ value was $10.7 \pm 3.6$ in the moderate/ severe disease group and $8.5 \pm 1.5$ in the mild disease group $(\mathrm{p}<0.001)$. The R-ABI and L-ABI values in both groups were similar ( $p>0.05$ ). Demographic characteristics, laboratory findings, hemodynamic parameters, and arterial stiffness measurements of the patients in moderate/severe and mild COVID-19 disease groups are presented in Table 2 . 
Table 1. Analysis of demographic, clinical, and laboratory findings of case and control groups.

\begin{tabular}{|c|c|c|c|}
\hline & $\underset{n=65}{\text { COVID-19 }}$ & $\begin{array}{c}\text { Control } \\
n=50\end{array}$ & p-value \\
\hline Age (years) & $66.9 \pm 12.3$ & $64.5 \pm 9.2$ & 0.213 \\
\hline $\begin{array}{l}\text { Gender } \\
\text { (female) n (\%) }\end{array}$ & $34(52.3)$ & $19(38.0)$ & 0.127 \\
\hline $\mathrm{BMI}\left(\mathrm{kg} / \mathrm{m}^{2}\right)$ & $27.7 \pm 3.6$ & $27.9 \pm 3.8$ & 0.804 \\
\hline Systolic BP, mmHg & $127.4 \pm 19.8$ & $140.8 \pm 24.7$ & 0.002 \\
\hline Diastolic BP, mmHg & $77.9 \pm 11.6$ & $80.6 \pm 13.9$ & 0.174 \\
\hline CAD, n (\%) & $12(18.5)$ & $17(34.0)$ & 0.057 \\
\hline Hypertension, n (\%) & $32(49.2)$ & $33(66.0)$ & 0.072 \\
\hline $\begin{array}{l}\text { Diabetes mellitus, } \\
\mathrm{n}(\%)\end{array}$ & $6(24)$ & $14(28)$ & 0.926 \\
\hline CMI scores & $3.3 \pm 1.9$ & $3.6 \pm 1.6$ & 0.354 \\
\hline $\begin{array}{l}\text { right-cardio-ankle } \\
\text { vascular index }\end{array}$ & $9.6 \pm 2.4$ & $8.5 \pm 1.1$ & 0.004 \\
\hline $\begin{array}{l}\text { left-cardio-ankle } \\
\text { vascular index }\end{array}$ & $9.4 \pm 2.7$ & $8.5 \pm 1.2$ & 0.01 \\
\hline $\begin{array}{l}\text { right-ankle-brachial } \\
\text { index }\end{array}$ & $1.04 \pm 0.14$ & $1.04 \pm 0.10$ & 0.886 \\
\hline $\begin{array}{l}\text { left-ankle-brachial } \\
\text { index }\end{array}$ & $1.06 \pm 0.26$ & $1.04 \pm 0.09$ & 0.984 \\
\hline
\end{tabular}

CAD: coronary artery disease; CMI: Charlson comorbidity index; BMI: body mass index. Bold values are determined as statistically significant.

When the ROC analysis was performed to distinguish moderate/severe COVID-19 patients from patients with mild disease, AUC $0.757(0.630-0.884)$ at cutoff point $>8.75$ for R-CAVI had $76 \%$ sensitivity and $56 \%$ specificity, and AUC $0.782(0.661-0.902)$ at cutoff point $>8.5$ for L-CAVI had $88 \%$ sensitivity and $58 \%$ specificity (Figure 1 ).

\section{DISCUSSION}

Under physiological conditions, the endothelium has a structure that prevents mononuclear cell adhesion at the blood-tissue interface. Inflammation caused by allowing white blood cells to enter tissues in order to fight microbial agents and aid in the healing of damaged tissues activates endothelial cells that cause the loss of vascular integrity, allows increased expression of adhesion molecules (such as VCAM-1 and ICAM-1), and allows endothelial cells to participate in the inflammatory response ${ }^{12}$. Increased expression of adhesion molecules stimulates the adhesion and migration of monocytes to the vessel wall, where these
Table 2. Analysis of demographic, clinical, and laboratory findings of patients according to the severity of COVID-19.

\begin{tabular}{|c|c|c|c|}
\hline & $\begin{array}{c}\text { COVID-19 } \\
\text { inpatient } \\
n=25\end{array}$ & $\begin{array}{c}\text { COVID-19 } \\
\text { outpatient } \\
n=40\end{array}$ & p-value \\
\hline Age & $70.7 \pm 13.1$ & $64.7 \pm 11.2$ & 0.051 \\
\hline $\begin{array}{l}\text { Gender } \\
\text { (female) n (\%) }\end{array}$ & $16(64)$ & $18(45)$ & 0.136 \\
\hline BMI $\left(\mathrm{kg} / \mathrm{m}^{2}\right)$ & $28.4 \pm 4.1$ & $27.3 \pm 3.2$ & 0.226 \\
\hline Systolic BP, mmHg & $124.4 \pm 20.2$ & $129.4 \pm 19.6$ & 0.174 \\
\hline Diastolic BP, mmHg & $76.0 \pm 8.7$ & $79.1 \pm 13.0$ & 0.245 \\
\hline CAD, n (\%) & $7(28)$ & $5(12.5)$ & 0.188 \\
\hline Hypertension, n (\%) & $18(72)$ & $14(35)$ & 0.004 \\
\hline $\begin{array}{l}\text { Diabetes mellitus, } \\
\mathrm{n}(\%)\end{array}$ & $6(24)$ & $6(15)$ & 0.363 \\
\hline CMI scores & $4.2 \pm 2.1$ & $2.8 \pm 1.6$ & 0.003 \\
\hline $\begin{array}{l}\text { right-cardio-ankle } \\
\text { vascular index }\end{array}$ & $10.8 \pm 3.4$ & $8.8 \pm 0.9$ & 0.008 \\
\hline $\begin{array}{l}\text { left-cardio-ankle } \\
\text { vascular index }\end{array}$ & $10.7 \pm 3.6$ & $8.5 \pm 1.5$ & $<0.001$ \\
\hline $\begin{array}{l}\text { right-ankle-brachial } \\
\text { index }\end{array}$ & $1.0 \pm 0.16$ & $1.06 \pm 0.11$ & 0.162 \\
\hline $\begin{array}{l}\text { left-ankle-brachial } \\
\text { index }\end{array}$ & $1.06 \pm 0.4$ & $1.05 \pm 0.1$ & 0.225 \\
\hline
\end{tabular}

CAD: coronary artery disease; CMI: Charlson comorbidity index; BMI: body mass index. Bold values are determined as statistically significant.

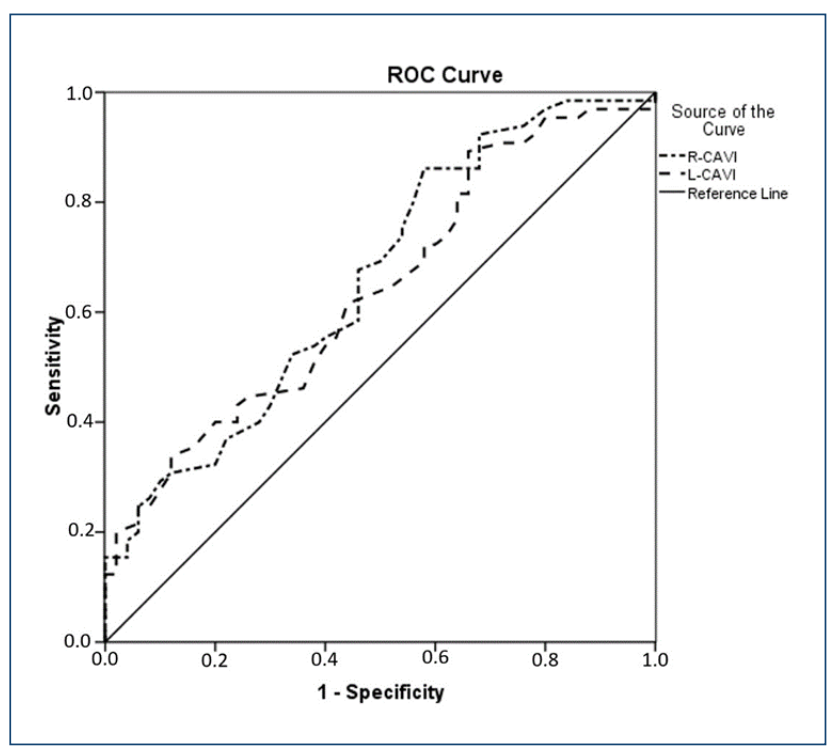

Figure 1. Receiver operating characteristic curve demonstrating the prognostic value of right-cardio-ankle vascular index and left-cardioankle vascular index in COVID-19 patients with moderate/severe and mild disease. 
cells further differentiate into macrophages, increasing vasculitis. Continuous endothelial cell activation results in subsequent endothelial dysfunction, which is the first step in atherogenesis and contributes to the development of distinct clinical features that characterize later stages of vascular disease ${ }^{13}$. While coronaviruses are known to cause endothelial dysfunction, it is remarkable that COVID-19 causes endothelial dysfunction in such a short period of time, and this situation is associated with prognosis. Researchers in New York City observed a seven-fold increase in large vessel strokes in patients younger than 50 years old during the 2-week period from March 23 to April 7, 2020, compared with a 2 -week period over the previous 12 years ${ }^{14}$ This study aimed to assess the functional change in arterial stiffness, which is commonly associated with endothelial dysfunction in COVID-19 patients, and to determine the prognostic significance of this condition. The presence of nitric oxide primarily regulates arterial stiffness, and CAVI, an indicator of arterial stiffness, somehow measures endothelial cell function ${ }^{15}$. In our study, R-CAVI and L-CAVI values were found to be significantly higher in the analysis between the case and control groups, as well as between moderate/severe patients and mild patients,

\section{REFERENCES}

1. Kant A, Kostakoğlu U, Atalar S, Erensoy Ş, Sevimli T, Ertunç B, et al. The relationship between diagnostic value of chest computed tomography imaging and symptom duration in COVID infection. Ann Thorac Med. 2020;15(3):151-4. https://doi.org/10.4103/atm. ATM_165_20

2. Libby P, Lüscher T. COVID-19 is, in the end, an endothelial disease. Eur Heart J. 2020;41(32):3038-3044. https://doi.org/10.1093/ eurheartj/ehaa623

3. Croce K, Libby P. Intertwining of thrombosis and inflammation in atherosclerosis. Curr Opin Hematol. 2007;14(1):55-61. https:// doi.org/10.1097/00062752-200701000-00011

4. Libby P. Once more unto the breach: endothelial permeability and atherogenesis. Eur Heart J. 2019;40(11):938-40. https://doi. org/10.1093/eurheartj/ehz081

5. Ackermann M, Verleden SE, Kuehnel M, Haverich A, Welte T, Laenger F, et al. Pulmonary vascular endothelialitis, thrombosis, and angiogenesis in Covid-19. N Engl J Med. 2020;383(2):120-8. https://doi.org/10.1056/NEJMoa2015432

6. BaeS, Kim SR, Kim MN, Shim WJ, Park SM. Impact of cardiovascular disease and risk factors on fatal outcomes in patients with COVID-19 according to age: a systematic review and metaanalysis. Heart. 2021;107(5):373-80. https://doi.org/10.1136/ heartjnl-2020-317901

7. Nishiga M, Wang DW, Han Y, Lewis DB, Wu JC. COVID-19 and cardiovascular disease: from basic mechanisms to clinical perspectives. Nat Rev Cardiol. 2020;17(9):543-58. https://doi. org/10.1038/s41569-020-0413-9 and the level of endothelial dysfunction was associated with the clinical status of the patients. The AUC value was determined by ROC curve analysis to be 0.757 for R-CAVI and 0.782 for L-CAVI, and the area under the quite high curve was located. The high sensitivity rates at the determined cutoff points also demonstrate the usefulness of the CAVI measurements.

\section{CONCLUSIONS}

The findings of the study lead us to believe that both R-CAVI and L-CAVI values can be used as prognostic indicators in COVID-19 patients. Given the global impact of the pandemic, well-designed large-scale clinical studies are required to convert this knowledge into clinical practice.

\section{AUTHORS' CONTRIBUTIONS}

EA: Conceptualization, Writing - original draft, Writing - review \& editing. AK: Data curation, Formal Analysis, Writing - review \& editing. GY: Data curation, Formal Analysis, Writing - original draft, Writing - review \& editing.

8. Laurent S, Cockcroft J, Van Bortel L, Boutouyrie P, Giannattasio C, Hayoz D, et al. Expert consensus document on arterial stiffness: methodological issues and clinical applications. Eur Heart J. 2006;27(21):2588-605. https://doi.org/10.1093/eurheartj/ehl254

9. Chirinos JA, Segers P, Hughes T, Townsend R. Large-Artery Stiffness in Health and Disease: JACC State-of-the-Art Review. J Am Coll Cardiol. 2019;74(9):1237-63. https://doi.org/10.1016/j. jacc.2019.07.012

10. Keller TT, Mairuhu AT, Kruif MD, Klein SK, Gerdes VE, Cate H, et al. Infections and endothelial cells. Cardiovasc Res. 2003;60(1):40-8. https://doi.org/10.1016/s0008-6363(03)00354-7

11. Gavriilaki E, Anyfanti P, Gavriilaki M, Lazaridis A, Douma S, Gkaliagkousi E. Endothelial dysfunction in COVID-19: lessons learned from Coronaviruses. Curr Hypertens Rep. 2020;22(9):63. https://doi.org/10.1007/s11906-020-01078-6

12. Wu M, Zeng FF, Wang R, Seto WK, Pai P, Chu P, et al. Atherosclerosis in patients with rheumatoid arthritis. Arthritis Rheum Curr Res. 2013;S5:002. https://doi.org/10.4172/2161-1149.S5-002

13. Libby P. Inflammation in atherosclerosis. Arterioscler Thromb Vasc Biol. 2012;32(9):2045-51. https://doi.org/10.1161/ ATVBAHA.108.179705

14. Oxley TJ, Mocco J, Majidi S, Kellner CP, Shoirah H, Singh IP, et al. Large-vessel stroke as a presenting feature of Covid-19 in the Young. N Engl J Med. 2020;382(20):e60. https://doi.org/10.1056/ NEJMc2009787

15. Zieman SJ, Melenovsky V, Kass DA. Mechanisms, pathophysiology, and therapy of arterial stiffness. Arterioscler Thromb Vasc Biol. 2005;25(5):932-43. https://doi.org/10.1161/01. ATV.0000160548.78317.29 